American Journal of Economics and Business Administration 3 (2): 377-389, 2011

ISSN 1945-5488

(C) 2010 Science Publications

\title{
The Effect of the Attacks of 9/11 on Organizational Policies, Employee Attitudes and Workers' Psychological States
}

\author{
Amy E. Hurley-Hanson, Cristina M. Giannantonio, Heidi Carlos, \\ Jessica Harnett, Melanie Jetta and Madeline Mercier \\ Argyros School of Business and Economics, Chapman University, \\ One University Drive, Orange, 92866 CA, USA
}

\begin{abstract}
Problem statement: The attacks of September 11, 2001 (9/11) on the United States have had a profound effect on organizations and their employees. These effects occurred in the days and weeks immediately following the attacks, as well as in the years since the attacks occurred. In commemoration of the tenth anniversary of 9/11, this study focuses on the impact that the attacks of September 11, 2001 have had on organizational policies, employee attitudes and workers' psychological states. Approach: Managers were surveyed regarding the effects of 9/11 on these issues. Results: The results of the study indicate that there was an immediate impact of the attacks on most of these issues. However, the results also suggest that the impact of these effects diminished over time. The results also varied by the size of the company with larger firms making more changes to their organizational policies than smaller firms. Conclusion: The effect of the attacks of 9/11 on organizational policies, employee attitudes and workers' psychological states may be felt for several years and should be investigated in future studies.
\end{abstract}

Key words: Psychological states, recruitment methods, organizational policies, Anti-Discrimination Committee (ADC), employee attitudes, human resources association, information technology

\section{INTRODUCTION}

September 11, 2001 started off as a regular Tuesday morning, with a clear sky described as "bright blue” (Levitas et al., 2002). By 8:30 that morning, some individuals were already at work, some were on their way to work and others were running errands, dropping their children at daycare, or picking up their coffee. It appeared to be a normal day, with the familiar sounds of a city on the move. Cars were honking their horns and planes were flying in the air above, but something felt wrong. Pedestrians later reported that the planes were louder and lower than normal (Levitas et al., 2002). At 8:46 a.m., the first plane crashed into the North Tower of the World Trade Center. September 11, 2001, a day that began so normally, rapidly became the day on which the worst terrorist attack in the history of the United States occurred.

It is estimated that 2,825 people died on September 11, 2001 in the attack on the World Trade Center. This number included 343 firefighters, 23 police officers, 658 Cantor Fitzgerald employees and 78 employees of the Windows of the World restaurant located at the top of the North Tower (Levitas et al., 2002). The people who were killed that day were bond traders, chefs, firefighters, computer programmers, administrative assistants, custodians, vice presidents and flight attendants. All "were imperiled simply because they showed up for work that day". On September 11th, showing up for work, cost many Americans their lives.

For most people, working is a common and relatively safe routine that Americans participate in everyday. A small minority of workers hold occupations where there is a high level of physical risk. For workers in these jobs, it might be expected that they will be placed in dangerous situations, be injured on the job, or even possibly be killed while at work. These are not the usual conditions faced by office workers on a daily basis. Yet the attacks of 9/11 showed Americans that innocent civilians performing their daily work routine could be the victims of terrorist attacks.

The attacks of 9/11 were not expected; nor were they were planned for. Ian Mitroff categorizes these types of attacks as "abnormal accidents" (Mitroff, 2004). These abnormal accidents, or "intentional attacks", include kidnappings, bombings, cyber or internet attacks (e.g. viruses), stealing and lying. Intentional attacks may be defined to include any attack

Corresponding Author: Amy E. Hurley-Hanson, Argyros School of Business and Economics, Chapman University, One University Drive, Orange, 92866 CA, USA Tel: (714) 628-7312 Fax: (714) 532-6081 
or event that is performed out of betrayal or sabotage (Mitroff, 2004). Mitroff (2004) also categorizes some types of events that may occur in the work place as "normal accidents". These include floods, earthquakes, human errors and system breakdowns (2004). While these events are not necessarily expected, companies may be better prepared for normal accidents than abnormal accidents (Mitroff, 2004).

As the tenth anniversary of the attacks of $9 / 11$ approaches, this study was conducted to understand how the workplace changed immediately after the attacks and how these changes have affected organizational policies, employee attitudes and workers' psychological states in the years following the attacks. The study examined the effects of $9 / 11$ on organizational policies, employee attitudes and workers' psychological states.

Organizational policies: The events of September 11, 2001 will go down in the annals of American history as one of the most devastating acts committed on our own soil. Within the span of a few hours, international terrorism, previously perceived as a violent abstraction that only happened in Europe and the Middle East, became an all too real phenomenon that could and did, happen in our own neighborhoods (Dwoskin and Squire, 2003). As a result of the attacks, not only was the country's cultural landscape forever changed, but organizational policies and business practices were modified because of the actions of 9/11. Since the attacks, government policies have restricted rights and freedoms that are the foundation of our nation, in an effort to prevent future acts of terrorism against the United States. In the years following 9/11, organizations have faced a myriad of issues in their quest to return to "business as usual" in a world permanently changed by terrorism (Dwoskin and Squire, 2003). Organizations have made a number of organizational policy changes since the events of 9/11. One organizational policy which has been affected by the events of $9 / 11$ is recruitment.

Recruitment: Since the attacks of 9/11, employers have made more efforts to increase the diligence with which they screen applicants during the recruitment process. Background checks, reference checks, work history and visa usage are utilized to identify and screen applicants who could harm the company, its workers, or themselves. Increased recruiting efforts allow employers to make more informed decisions when hiring candidates. According to Bob Crowley, director of human resources for American Hospitality Concepts, Incorporated (AHCI), the cost of hiring a manager can run upwards of $\$ 10,000$ to $\$ 20,000$ and a company is working in its own best interests to do the appropriate research to make the wisest investment in its human capital.

Pre-screening efforts pre-9/11 were different from the practices in place in a post-9/11 world. According to ChoicePoint, one of the largest employment-screening companies in the country, companies were previously only interested in an applicant's criminal record in their country of residence. Since 9/11, businesses also conduct national criminal-file checks, more detailed background checks into an applicant's history (upwards of ten years) and pre-screening of all applicants for all levels of positions. By making more rigorous practices consistent for all levels of candidates, companies are demonstrating that no individual will be able to skip a step in the hiring process.

According to Apfel, some companies have adopted a modified screening process for their employees to defray the costs of prescreening. Marie Callender's Restaurants, a 170-unit chain based in Orange, California, changed their recruiting practices post-9/11 to a tiered system for background checks. Hourly employees undergo at least two interviews and must provide four references; bookkeepers receive criminal and credit checks; and managers go through criminal, credit and work-history checks. By having a tiered system in place, the company makes the appropriate screening expenditure for each level of candidate being hired.

For certain jobs, an extensive background check is essential. For example, no one wants to hire a taxi driver with multiple driving violations or an assistant controller with a record of bounced checks. According to ADP Screening and Selection Services, there has been an increase in background checks between 2001 and 2004 upwards of 65\%. However, problems with background checks do exist. Errors are common, theft of confidential information occurs, background checks may fail to identify potential wrongdoers and they may require candidates to disclose information that is irrelevant to job conduct. In these instances, employers are cautioned to ensure that their reasons for denying candidates employment are job-related and not based on the results of the background check or the screening system in place at that organization.

Background checks are not the only source of information used to gather information about a candidate's history. Prior to 9/11 employers typically utilized a system that emphasized a combination of a candidate's work history, personal references and business references. After the events of 9/11, those practices have changed. In a Society for Human 
Resource Management (SHRM) survey, it was reported that employers are moving away from utilizing only a candidate's work history, personal references and business references and towards increased usage of credit, criminal and character data checks prior to hiring (Society of Human Resource Management). In 1996, $92 \%$ of employers checked references and $84 \%$ checked work histories. In 2003, both of these numbers dropped substantially, to 80 and $79 \%$, respectively, while the use of other methods such as credit and criminal checks increased. Frieswick attributes the current practices to a fear of liability. Fearing a negligent hiring lawsuit if the company has failed to do its due diligence could cost the company hundreds of millions of dollars in litigation costs. Taking appropriate steps to ensure that a company is doing due diligence will determine the extent to which they utilize background and reference checks.

The Federal Fair Credit Reporting Act governs those companies that do background checks through a third-party service. The services it covers include credit reports, investigative consumer reports (including interviews with neighbors and associates) and background checks. Under Federal Trade Commission rules, any consumer credit information discarded by a company must be destroyed properly to ensure that it is not retrieved or reused. Breaches at Bank of America and Time Warner demonstrate that this is a privacy issue that needs continued vigilance as employers are liable if the information is stolen or misappropriated.

Similarly, during the interview process, employers need to ensure they avoid asking questions designed to elicit information about protected classifications (Dwoskin and Squire, 2003). Federal and state antidiscrimination laws restrict an employer's ability to solicit information such as ethnicity, national origin and religious affiliation. Bona Fide Occupational Qualifications (BFOQs) allow an organization limited instances in which they may hire and employ individuals on the basis of protected characteristics deemed necessary to the normal operation of that particular business or enterprise. With BFOQs, the burden of proof always lies with the employer. The company must ensure that their recruiters and hiring managers are trained appropriately to avoid situations that could potentially find them in violation of existing anti-discrimination laws.

One final area of recruitment that has undergone scrutiny in the aftermath of $9 / 11$ is the program. The H1B Visa program is the primary work visa and work permit in the United States. The H1B Visa was introduced as a way to enable highly skilled international professionals and students the opportunity to live and work in the United States, with professionals eligible to remain in the U.S. for up to six years. In the wake of $9 / 11$, concern has shifted as efforts to restrict access to the U.S. could impact the flow of skilled foreign talent that has been a primary source of hiring in certain industries. According to the H1B Visa Center, other areas that could be impacted include computing and Information Technology (IT), health care, finance and accounting, teaching, legal, public relations, marketing and advertising, sales, management and engineering. The United States Citizenship and Immigration Services (USCIS), formerly the Immigration and Naturalization Service (INS), does not have plans to alter the program, but the program will likely be re-evaluated if it is determined that any terrorists entered the country on a visa.

Diversity and discrimination: Another organizational issue that has experienced change post $9 / 11$ is discrimination. While all Americans were affected by the events of 9/11, dramatic changes occurred for ArabAmericans living and working in the United States. The experiences of Arab-Americans post 9/11 has generated a new word in the American lexicon: Islamophobia. According to Sway (2006), Islamophobia consists of violence against Muslims in the form of physical assaults, verbal abuse and the vandalizing of property. It also includes discrimination in employment where Muslims experience unequal opportunities and exclusion from jobs and other work opportunities.

According to the U.S. Equal Employment Opportunity Commission (EEOC), the number of workplace discrimination claims peaked in the weeks following the attacks of 9/11 and continued in high numbers from September 2001 through May 2002 with roughly a $2.5 \%$ increase from the same period in the previous year. Some areas specifically impacted within the realm of discrimination included adverse employment actions, hostile work environments, religious accommodations and political expressions (Dwoskin and Squire, 2003).

Organizations need to clearly understand that employees' religious rights are protected by Title VII of the Civil Rights Act of 1964. The Act states that employers must accommodate employees' religious practices, unless the employer can prove that undue hardship, significant difficulty, or expense would result. According to Adelman, efforts to increase awareness of religious accommodation post 9/11 include a seven fold increase in The Council on American-Islamic Relations' (CAIR) pamphlet, The Employer's Guide to Islamic Practices; a lecture called "Islam and the U.S". for the staff of the Educational Testing Service (ETS) which administers standardized tests such as the SAT 
and GRE; the Equal Employment Opportunity Commission's (EEOC) distribution of fact sheets outlining guidelines for accommodating religious practice in the workplace; and programs promoting religious tolerance and diversity offered by the Society of Human Resource Management.

According to HR Focus, it is important for employers to ensure that their workplace is protected from discrimination based on religious and ethnic origin. In addition to legal compliance, employers who protect employees from discrimination are less likely to be sued and may be able to avoid strife which can affect productivity. Most claims of discrimination were based on religious attire or appearance (e.g., headscarves or beards), racist comments on perceived ethnic origin and incidents involving prayer. Numerous cases have been filed against employers who do not make reasonable accommodation for religious differences. Table 1 identifies some practices which may be potentially discriminatory and which could be easily changed to allow for religious accommodation'

Research suggests that firms that have zero tolerance policies regarding religious discrimination tend to have fewer complaints. A letter circulated immediately after $9 / 11$ by the Chairman of Price Waterhouse Coopers (PWC) made the company's zero tolerance policy very clear. Other efforts to reiterate the company's discrimination policy include having brown bag lunches to provide information regarding Islam and religious tolerance, circulating a diversity newsletter, providing meeting reminders to managers regarding when to schedule business lunches with Muslim colleagues and offering a few floating holidays for Ramadan. Employees of PWC are expected to tell their clients about religious practices that may impact their business relationships. PriceWaterhouseCoopers was clear about not wishing to offend their clients. For example, male employees whose religion does not permit them to touch women who are not family members, are asked to explain to their female clients that they are unable to shake their hands because of their religion. In this example regarding the business practice of shaking hands, the company was clear about not wishing to offend their clients and making accommodation for religious practice. PWC was very clear on the company's intent and was proactive in ensuring that their guidelines were appropriate and consistent.

Another form of discrimination in the workplace is disparate treatment (Babcock, 2006). This type of discrimination involves differential treatment of employees on the basis of protected characteristics. For example, an Iraqi-American contacted the AmericanArab Anti-Discrimination Committee (ADC) claiming that his employer refused to pay medical expenses for a serious illness that should have been covered by health insurance. He later learned that a non-Arab co-worker with the same job and tenure was covered for a similar illness. While the EEOC, ADC and CAIR continue to see increases in the total number of discrimination claims, employers must remain diligent and act consistently to avoid claims of disparate treatment discrimination. In a statement by EEOC Chair Cari Dominguez, immediately following the September 11 terrorist attacks, he said "Our laws reaffirm our national values of tolerance and civilized conduct... The nation's workplaces are fortified by the enduring ability of Americans of diverse backgrounds, beliefs and nationalities to work together harmoniously and productively". His statement suggests that organizational policies were affected by the events of 9/11. below:

The following hypotheses are formally stated

H1: Organizations have taken measures to address workforce diversity post 9/11.

H2: Recruitment methods have been modified post 9/11.

H3: Sensitivity training has been implemented to reduce discrimination post 9/11.

Employee attitudes: Much research has been conducted on the effects of the attacks on employee attitudes such as job satisfaction, employee engagement and motivation in the workplace. The events of 9/11 may have influenced the attitudes of employees working far from the physical locations of the attacks (e.g. the World Trade Center in New York City and the Pentagon in Virginia). Research suggests that some of the outcomes that resulted from the attacks include employees reevaluating the meaning of work, increased loyalty and commitment to one's organization, greater employee caring for one another, need for increased time with family as opposed to spending time at work and more negative job attitudes (Ryan et al., 2003; Miller, 2000; SHRM/eePulse, 2001).

A study conducted by Ryan et al. (2003) examined whether widespread effects of $9 / 11$ on employee attitudes exist. It was suggested in the popular press that employee attitudes might become more negative in response to the attacks. According to Wortman and Silver (1989), it is expected that employees need to go through a period of depression in order to recuperate from a stressful event. Their research also indicated that 
Table 1: Potentially discriminatory practices

Scheduling an interview or job test conflicting with religious needs

Inquiring about an applicant's future availability

Maintaining a restrictive dress code

Refusing to allow observance of a religious holiday.

Requiring an employee to pay union dues when an employee's religious practice prohibits it.

Making a worker participate in activities such as medication, yoga, or biofeedback, when they conflict with a worker's religious views.

How to build a strong accommodation program

Making it clear that employees may express religious views as long as they are not imposed on others.

Emphasizing that the company will make efforts to accommodate religious expression, but that the company's main mission is to achieve its business objectives.

Making safety, not religion the main issue.

Starting a training program with supervisors and managers. Suggesting for the training program include:

Providing a statement by the company that it supports expressions of patriotism and national unity by employees.

Acknowledging that all Americans feel victimized by recent events, but the organization is a place of business and employees should behave accordingly.

Reminding management and employees that Arab and Muslim co-workers are fellow citizens, not terrorists; and that all religions, nations, and communities have fringe elements that act in ways that others disapprove of or despise.

Stressing the need to be vigilant about signs of prejudice, harassment, or discrimination.

Providing ways to address inappropriate conduct.

Creating a memo to the workforce.

Table 2: Comparison of two cities

\begin{tabular}{lll}
\hline & New York & Los angeles \\
\hline Total population & $8,168,388$ & $3,819,951$ \\
Median household income & $\$ 38,293$ & $\$ 36,687$ \\
No. of businesses & 103,313 & 235,085 \\
Gross metropolitan product & 901.3 million & 581.3 million \\
Caucasian/White & $45 \%$ & $47 \%$ \\
African American & $27 \%$ & $11 \%$ \\
Asian & $10 \%$ & $10 \%$ \\
Hispanic/Latino & $27 \%$ & $47 \%$ \\
\hline
\end{tabular}

some individuals may never show signs of intense distress. Lazarus (1991) cognitive-motivationalrelational theory provides one model of reactions to stressful events. The theory suggests that one's primary appraisal of an event involves assessments of goal relevance (what, if anything, is at stake), goal congruence (is the event harmful or beneficial) and goal content (what type of ego involvement is occurring). The study also described secondary appraisal, which involves decisions about whether there are attributions of accountability and control, whether one feels one has coping potential and whether one has future expectations of positive or negative life changes. The components of the appraisal process lead to different emotions such as anger, anxiety and sadness. According to Lazarus (1991), the secondary victims of 9/11 most likely appraised the events as harmful, threatening to one's personal security and way of life, outside one's control and leading to expectations of future negative changes in lifestyle and other future negative events. However, according to Weiss, attitudes are not affective constructs like emotions. Similar to job satisfaction, attitudes are also evaluative constructs, but they are not states and do not have the same physiological correlates as emotions. Lazarus (1991) model may indicate the emotional outcomes of $9 / 11$, but it does not address whether emotional states affect job attitudes (Ryan et al., 2003).

According to Hobfoll's Model of Conservation of Resources (Hobfoll, 1989), reactions to stressful events may cause people to attempt to retain, protect and build resources and cause them to feel threatened by the potential or actual loss of resources. Resources include object resources (house, car), conditions (marriage, seniority), personal characteristics (self-esteem) and energies (time, money). Many people may have viewed the attacks of 9/11 to be threatening because they affect a change in one's way of life, as well as the threat of physical harm and economic instability. This model suggests that individuals cope with stress by utilizing other resources to offset their losses or by reevaluating resource threats. For example, individuals may reevaluate their resource loss by looking at how lucky they are in comparison with what could have happened. This suggests that individuals may consider the effects of 9/11 in terms of social comparison theory, wherein they would use downward comparisons to make oneself feel better about one's own situation. In their research, Ryan et al. (2003) make the assumption that employee attitudes will be more favorable if downward comparisons were made after 9/11 and were compared with the typical upward comparison made pre 9/11 (Ryan et al., 2003).

Some research on job attitudes supports the idea that negative emotions associated with 9/11 may lead to more positive job satisfaction, or at least have no negative effects on job satisfaction. Due to downward comparisons, individuals may have greater life satisfaction, which would lead to greater job satisfaction (Bergermaier et al., 1984). Researchers suggest that job and life satisfaction may influence each other such that people high in life satisfaction tend to 
enjoy their jobs more than people low in life satisfaction. It is also suggested that job satisfaction contributes to life satisfaction (Judge and Watanabe, 1993). The events of $9 / 11$ may have influenced the affective states of individuals (emotions, moods, stress), which may have affected evaluations of one's job indirectly by leading to more positive evaluations of one's life (Ryan et al., 2003).

The study conducted by Ryan et al., 2003) found that the attacks of 9/11 did not have a meaningful impact on work attitudes and employees' feelings about the subjects' work. Their findings are consistent with a similar study conducted by Macey. Macey's study found that there were no differences in pre- and post9/11 attitudes amongst employees in Fortune 100 companies. While this does not indicate that individuals overall were not affected, the findings of this study suggest that employees' perceptions of their jobs and organizations may be unchanged, even though several changes within the workplace had occurred (Ryan et al., 2003).

A study conducted by Aon Consulting examined the commitment of employees to their respective employers, as well as what employers did to heighten employee commitment. The results of the study revealed that there was a shift in work-life balance priorities, with employees wanting to spend more time with their families; that commitment to their respective employers had increased; that employees felt that their employers had responded to the events of 9/11 well; and that employees had favorable views on the state of the economy. However, one significant finding from the study found that employees expressed less confidence in the future of their employers. Overall, the study found that following 9/11 employees had more positive perceptions of their organizations' recognition of the importance of personal and family life (Burke, 2005). Results of a workplace trends study conducted by (Society of Human Resource Management), suggest that people began reevaluating their lives, the meaning of work and those aspects of work that contributed to their motivation following the attacks of 9/11. In particular, people reported that were beginning to examine the amount of time they spent away from their families due to work and that they had started to revisit the dreams they had prior to working in the jobs they held when the attacks occurred. According to the study, while the weak economy prevented people from making drastic changes, they were making subtle lifestyle adjustments.

Respondents reported spending more time with friends and family and less time at work. Many people considered volunteer opportunities and community service, decreased their level of travel and increased the time spent on personal activities (Society of Human Resource Management). Other studies found an increase in the number of people changing jobs following the attacks of 9/11 as more people searched for greater meaning in their work. Some authors have suggested that $9 / 11$ became a catalyst for examining what an individual's work contributed to the world at large (Wrzeniewski, 2002).

For some individuals, the events of 9/11 created a new organizational reality. This was particularly true for workers who were physically located in the World Trade Center (WTC). Cantor Fitzgerald (CF), an international brokerage firm that operated on the 101st through the 105th floors of Tower One of the WRC, lost 685 employees in the attacks. Operations at this location were essentially decimated. The firm lost a greater percentage of its employees than any other single company impacted by 9/11 (Seeger et al., 2005). As a result of the vast loss of life and devastation, Howard Lutnick, CEO of CF offered a new justification for the firm's existence: “There is only one reason to be in business-it is because we have to make our company be able to care of our 700 families".

Lutnick's statement gave a personal, human face to the tragedy. Employees had a renewed vision of what CF's future would entail. Employees knew that they would be working to fill orders to help provide for the families that were affected by the crisis. New values emerged as a result of the attacks, such as a sense of community and corporate social responsibility. The surviving employees' main concern became helping the families of the victims, moving beyond profit-making (Seeger et al., 2005).

O'Neill and Partners, another financial services firm that was housed in the WTC, lost 39\% of its workforce, two-thirds of its management committee and its entire office. However, one year after the attacks, the firm had recovered and was performing at a higher level than before the attacks. A sense of moral purpose had emerged which unleashed motivation amongst the employees to pull together and succeed. The firm's leadership also played a key role in handling anxiety and grief. This culture encouraged and supported team work and self-management, which also helped in maintaining unity and sense of purpose in the face of tragedy (Burke, 2005). Additional research by Kelly and Stark reported evidence of increased organizational unity amongst impacted organizations. Executives and employees in financial services firms with offices in the WTC and adjacent buildings were interviewed. In the face of uncertainty, strong personal ties amongst employees, lateral self-organization in the form of teams and non-hierarchal relations contributed to organizational unity and as a result, were critical to the recovery process (Burke, 2005). 
The attacks of $9 / 11$ were a significant and devastating event for many organizations, especially airlines, travel companies, government agencies and financial services organizations. Firms such as Cantor Fitzgerald were essentially destroyed, but were able to bounce back as a result of a renewed sense of purpose, motivation and unity. Crises disrupt the status quo and may allow for new assumptions, methods and organizational values to emerge (Seeger et al., 2005). Despite this positive anecdotal evidence of increased employee attitudes post 9/11, it is hypothesized that:

H4: In the years following 9/11, work attitudes and job satisfaction declined and were negatively affected by the attacks.

Workers' psychological states: After the attacks of 9/11 Human Resource professionals nationwide frequently reported that dealing with employees' depression and post-traumatic stress becoming a large part of their jobs. The attacks of September 11, 2001 did affect the psychological states of employees. In the months and years following 9/11, HR departments dealt with helping employees to cope with depression, stress and anxiety as a result of the attacks. Human Resource professionals played a large role in helping employees to cope with the aftermath of the attacks, especially in the area of mental health. In the Society of Human Resource Management issue of HR Magazine, a number of HR professionals from companies around the country spoke about ways in which they helped their employees cope with the tragedy. HR professionals emphasized and encouraged the use of company Employee Assistance Programs (EAP) as an extra source of support. In most of the companies featured, HR found themselves helping executives balance the emotional needs of employees, while at the same time developing strategies to move the company forward. According to Kondrasuk (2004), HR managers were actively helping their employees in various ways, including: "allowing employees to delay or cancel traveling to take time off, provided financial aid to victims, canceling meetings, encouraging employees to help each other and to expect tighter security". Much effort was spent helping employees transition back to work from absences for post-traumatic stress.

In helping their subordinates cope with the aftereffects of 9/11, managers had to display a level of sensitivity that may have been unfamiliar to them in their prior experience. HR professionals were instrumental in helping managers understand how to support their employees, while at the same time, establishing reasonable performance expectations given the circumstances. Overall, a need for increased sensitivity for the emotional and mental needs of employees was emphasized by management with the help of HR professionals within organizations (Burke, 2005). Instances of employers losing good employees as a result of not receiving the help and support they needed after such an event was also reported. In one particular instance, a New York City-based employee who was working for a Nebraska-based employer received no contact from her home office following 9/11 to see how she was doing. As a result, she became increasingly unhappy, felt devalued and unsupported and eventually resigned four months later (Society of Human Resource Management). A study conducted by Aon Consulting found that organizations directly affected by the 9/11 attacks were likely to provide crisis counseling to their employees, while employers less directly affected provided less support or offered nothing at all.

Following 9/11, stress, anxiety and depression amongst employees became a significant issue for many organizations. This was true regardless of whether the organization was directly impacted by the terrorist attacks or not. Although depression and anxiety were expected immediately after the attacks, it was unclear how far reaching into the future these effects were felt. The present study explores depression and post-traumatic stress among employees immediately after the attacks and in the years subsequent to the attacks. The events of 9/11 differ in focus from traditional disaster research in that the effects were not limited to an isolated geographic region, they were a man-made disaster, as opposed to a natural disaster and they were an intentional disaster, as opposed to being a result of human error or negligence. According to the research of Holloway and Fullerton (1994) and Jacobs and Kulkarni (1966), there is a sense of vulnerability and fear that results from terrorist incidents that is more pervasive and persistent than from other disasters. This suggests that terrorist-related events may pose greater mental health consequences than are experienced with other types of disasters (Ryan et al., 2003).

Much research on the psychological effects of the attacks was conducted in the time immediately following $9 / 11$, with time periods varying from days after to two or three years following 9/11. Of the many issues that organizations dealt with immediately following $9 / 11$, employee stress, anxiety and depression was a significant issue. According to research by Knudsen et al. (2005), there was a significant increase in the number of depressive symptoms during the four weeks after the attacks. Their research focused on 
"communal bereavement", defined as the "widespread experience of distress among persons who never met the deceased". Communal bereavement is likely to occur when social institutions fail to keep people safe from harm, which is manifested in the loss of life and causes societal level distress because central expectations of the effectiveness of social institutions are challenged (Catalano and Hartig, 2001). The attacks of $9 / 11$ would seem to be an event that would likely result in communal bereavement, given that it resulted in the greatest terrorism-related loss of life in U.S. history (Schlenger et al., 2002).

Additional studies regarding depressive symptoms suggest empirical support for the argument that there was a period of communal bereavement immediately following the attacks of 9/11 (Catalano and Hartig, 2001). The results of Knudsen et al. (2005) study regarding depressive symptoms are consistent with other national data that have pointed to negative psychological consequences being experienced by the U.S. adult population, as well as New York City residents (Schlenger et al., 2002; Silver et al., 2002). Respondents to the Knudsen study interviewed within the first two weeks after the attacks reported significantly more depressive symptoms than their pre9/11 counterparts. During the following two-week period, an elevated number of depressive symptoms continued to be reported. As time went on, however, respondents that were interviewed between four and six weeks after the attacks, showed no further significant differences between the pre $9 / 11$ and post $9 / 11$ groups studied. The finding of diminished depressive symptoms over time was consistent with previous studies related to this subject. Overall, the results of this particular study showed that "while the terrorist attacks of 9/11 changed many aspects of American life, their influence on Americans' collective well-being was likely limited to a relatively short time frame immediately following the attacks (Knudsen et al., 2005)”.

In addition to the psychological effects of disasters on direct survivors, peripheral victims may also be impacted by disasters such as the attacks of 9/11. Peripheral victims are described as people who, but for chance themselves might have been primary victims or who are indirectly or vicariously involved (Knudsen et al., 2005). Less is known about the psychological effects of the attacks on peripheral victims, which may include colleagues who work for the same company, but at other geographic locations from the site of the attacks. The number of potential peripheral victims associated with the attacks of 9/11 may be difficult to estimate. One might argue that all American workers were peripheral victims to the attacks of $9 / 11$ and that it is important to capture these workers' psychological states as well as those of direct survivors. The following hypothesis is formally stated below:

H5: The events of 9/11 resulted in an increase in depression and post-traumatic stress amongst employees in the years following the attacks.

\section{MATERIALS AND METHODS}

Participants: Human Resources professionals located in Downtown Los Angeles, who were also members of the Professionals in Human Resources Association (PIHRA) were chosen as the participants for this study. A survey was sent out via email to 446 PIHRA members; 42 completed responses were received, yielding a $9.4 \%$ response rate. The respondents were primarily white/Caucasian women, in their forties and fifties, who had completed some college course work. Most respondents held jobs in middle to upper management (HR managers and directors) and the majority of the respondents had been with their organization for 10 years or less. Respondents worked in a variety of industries and organizations of all sizes were represented. The downtown Los Angeles geographic location was selected due to the size and importance of the metropolitan area. By using Los Angeles, the researchers intended to mirror the demographics of the downtown area of New York, as both cities are considered major metropolitan areas and are also major U.S. port cities. Below is a statistical comparison of the two cities.

Los Angeles has also been identified as a likely future target of terrorist activity. In addition, details of a plot to use airplanes to attack downtown Los Angeles was released earlier in 2006. The same individual that lead the attacks of 9/11 was also planning on using bombs in their shoes to breach the cockpit doors and take control of the plane. The plan was to crash the plane into the US Bank building, the tallest building in Los Angeles in 2002. However all of the participants in the plan were arrested before they could go through with the attacks (http://www.cnn.com/2006/POLITICS/02/09/bush.terro r/index.html).

Instruments/Data Collection The data was collected through a 48 question survey consisting of Likert scale responses measuring individuals' opinions on the topics of organizational policies, employee attitudes and workers' psychological states. The survey also included questions on the following demographic information on respondents and their company profile: gender, 
ethnicity, age range, education, years in current position, job title, career level, location of their organization's corporate office, size of organization and industry type. The survey was created and administered using an on-line survey administration web site. The researchers did not have direct contact with the survey participants, as distribution of the survey was facilitated by PIHRA. A representative from PIHRA distributed the survey link including a short cover letter via email to further protect the anonymity of the participants.

\section{RESULTS}

Organizational policies: As it relates to the recruitment and diversity and discrimination hypotheses of the effects of $9 / 11$ on organizational polices, the results are as follows:

H1: Organizations have taken great measures to address workforce diversity post-9/11. Of those who responded to the questions related to an increase in measures addressing workforce diversity post-9/11, 68\% of the respondents disagreed that there was an increase in efforts to diversify its employee base.

H2: Recruitment methods have been significantly modified to address changes in the workforce practices post 9/11. Of those who responded to questions related to were recruitment methods significantly modified to address changes in workforce practices post-9/11, 30\% of the respondents agreed that recruitment efforts had changed significantly. However, a majority of the respondents (35\%) neither agreed nor disagreed and 32\% responded that they disagreed recruitment efforts had changed post-9/11.

H3: There has been an increase in sensitivity training implementation to ensure organizations are not discriminating in the workforce since 9/11. Of those who responded to questions regarding sensitivity training implementation post-9/11, 46\% of the respondents agreed that there was an increase in diversity and sensitivity training and $62 \%$ also disagreed that there was an increase in discrimination claims in their organization. The results of the research show a high level of significance when comparing the control variable of organizational size to the various dependent variables: recruitment, diversity, employee morale, job attitudes, commitment, work-life balance, depression, motivation.

For the purpose of this research, the organizational size classifications were organized as follows: Less than 100 employees; Between 100-999; Between 1,0004,999; Between 5,000-9,999; More than 10,000 employees. ANOVA was used to analyze the survey data. A significance level of less than $0.05(p<0.05)$ was used to identify the relevant results as it relates to the variance of means for the relationship between organizational size and the various dependent variables tested.

Significant results were obtained when analyzing the relationship between organizational size and increased effort to recruit international candidates five years following 9/11 $(p<0.028)$. As illustrated in Fig. 1, larger organizations, those with more than 10,000 employees reported an increased effort to recruit international candidates. Smaller organizations either disagreed or neither agreed, or disagreed. Larger organizations typically have international operations and would more likely have a need to recruit international candidates.

Significant results were also obtained when analyzing the relationship between organizational size and the importance of discrimination in workplace issues years after $9 / 11(p<0.003)$. As illustrated in Fig. 2, organizations with 1000-4999 employees or greater ranked discrimination in the workplace as a medium to high importance issue, compared to smaller organizations. Smaller organizations generally ranked the issue of discrimination in the workplace lower.

Finally, significant results were obtained when analyzing the relationship between organizational size and an increase in diversity and sensitivity training five years following $9 / 11 \quad(p<0.030)$. Larger organizations, those with 10,000 employees or more increased diversity and sensitivity training post 9/11. Organizations with less than 10,000 employees either disagreed or neither agreed or disagreed that diversity and sensitivity training increased five years following 9/11.

Employee attitudes: Hypothesis H4 was not supported. About 59\% of the respondents disagreed that job satisfaction was negatively affected by the effects of $9 / 11$. About $48 \%$ of the respondents neither agreed nor disagreed that employee commitment increased after the events of $9 / 11$. However, $43 \%$ of the respondents agreed that emphasis on work-life balance increased post 9/11. With respect to organizational size, as illustrated in Fig. 3, the relationship between organizational size and the importance of employee morale five years following 9/11 was significant $(\mathrm{p}<0.048)$, with larger organizations ranking employee morale lower when evaluating its importance in their workplace today.

The relationship between organizational size and an increase in work-life balance five years following $9 / 11$ was also significant $(p<.019)$. As illustrated in 
Am. J. of Economics and Business Administration 3 (2): 377-389, 2011

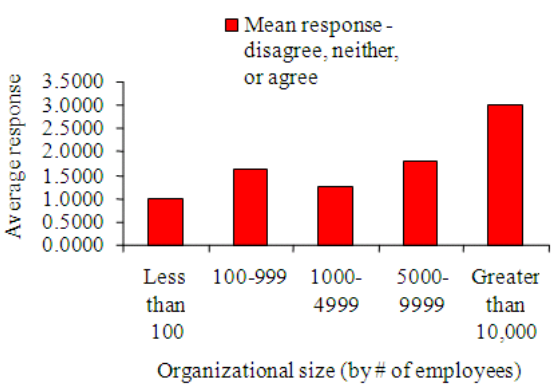

Fig. 1: Increased recruitment of international candidates

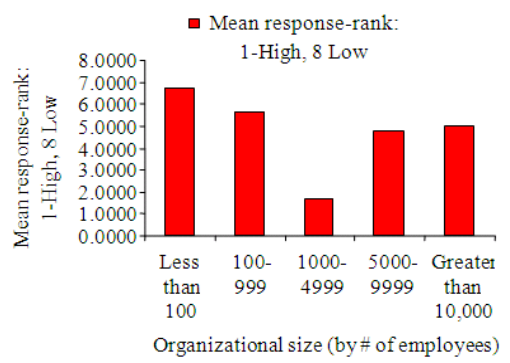

Fig. 2: Importance of Discrimination in the Workplace Issues, 5 years following 9/11

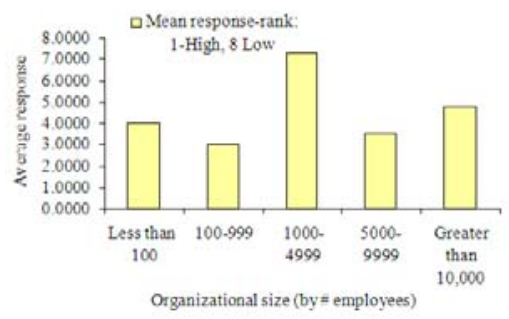

Fig. 3: Importance of employee morale 5 years following $9 / 11$

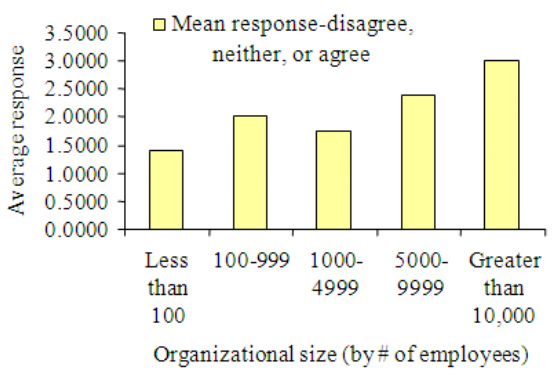

Fig. 4: Increased emphasis on work-life balance

Fig. 4, organizations with 10,000 or more employees generally agreed that their employers increased emphasis on work-life balance post 9/11.
Psychological states: Hypothesis H5 was not supported. About $57 \%$ of the respondents disagreed that there was an increase in post-traumatic stress post 9/11 and $62 \%$ disagreed that there was an increase in depression amongst employees post 9/11.

Limitations: There were many issues to consider in analyzing the results of this study. One such issue included the timing of the study. Participants were asked to recall situations that occurred several years after the attacks of 9/11. Although the individuals surveyed may have reacted strongly to the attacks and have vivid recollections of that time period, the effects and memories from that period may have diminished over time. Another limitation involves other factors independent of 9/11 that have resulted in changes to the work place. Since 9/11, there have been many significant events that have caused workplace changes such as, Sarbanes-Oxley, Enron, as well as the downturn in the economy over the last few years. It is not possible to determine if changes to the organizational policies being surveyed were a direct result of the events of 9/11.

Demographics of the participants surveyed would also be considered a limitation of the research. Due to the nature of the HR field, the participants were predominantly women and the researchers were not able to obtain a significant comparison amongst genders. Another limitation involved industry demographics. Since the study was not focused on one particular industry, HR professionals in industries that may not have been affected significantly by the attacks may have skewed the results. A majority of the individuals surveyed were part of organizations with headquarters on the West Coast and due to location, may not have had significant changes as a result of the attacks.

A final limitation involves the career stages of the participants. Some of the participants were in the early stages of their careers. Their responses may have been based on speculation on what they think may have happened, as they may have not been directly involved in the decision-making process, as opposed to those participants in upper-level management positions. The researchers used structured and closed ended questions for the survey and therefore the respondents may have been limited in their answers. The surveys yielded a 9 . $4 \%$ response rate since it was conducted via email, which may affect the generalizability of the results. Major portions of populations may not be represented and therefore those non-participants may have different opinions than those who did respond. 
Am. J. of Economics and Business Administration 3 (2): 377-389, 2011

\section{DISCUSSION}

The research and the results combined have shown that 9/11 has had a significant impact on organizational policies. Although some policies were more influenced by the impact of $9 / 11$, overall, it was found that $9 / 11$ changed the workplace in many ways. The results of this study suggest that the events of 9/11 significantly impacted organizational policies in the areas of recruitment and diversity training. The events of 9/11 have an impact on employee attitudes, but not on workers' psychological states over time. Previous research indicated that negative emotions associated with 9/11 may lead to more positive job satisfaction, or at least have no negative effects on job satisfaction at all. According to the data, job satisfaction, work attitudes and employee morale were not impacted significantly by the events of $9 / 11$ in that it did not have long-term effects on these issues. As a result, the data supports previous research.

Based on the results of the survey data, the majority of respondents neither agreed nor disagreed with the hypothesis that recruitment efforts changed significantly post-9/11. Roughly the same percentage of respondents both agreed and disagreed that recruitment efforts changed significantly. Although the available literature shows increases in efforts for due diligence and consistency, this is not reflected in the survey information available.

Of significance to note, $68 \%$ of individuals felt their organizations were working to fix diversity its employee base. However, an overwhelming $62 \%$ felt there was an increase of discrimination claims in their organization. Again, the available literature paints a completely different story with an overwhelming variety of statistics and examples of workplace discrimination claims. It is interesting to note that 39\% of respondents felt that their organizations were being more proactive in addressing discrimination claims. This too is supported in the literature and that those companies that continue to address claims of discrimination proactively tend to have fewer resultant claims.

Survey results indicated that respondents felt that in their organizations, workplace discrimination claims did not increase after $9 / 11$, nor were influenced by the events of $9 / 11$. Since the attacks of $9 / 11$ had such a great impact on Americans as a whole, they perhaps served as a way to bring Americans together rather than cause them discriminate against each other in the workplace. Also the attacks could have made American more cognizant of their biases and thus more cautious in the workplace. Interestingly to, the results showed that smaller organizations did not find that discrimination in the workplace was an issue during the 5 years following 9/11; however larger organizations did consider this an important issue in the workplace. Smaller organizations force workers to interact more closely with everyone in the organization making it difficult for employees to hide their prejudices. In larger organizations, it is easier for employees to essentially "get lost in the crowd", thus making it less difficult to hide their opinions or prejudices since they are one of many. In addition, the larger the organization is, the more opportunities for a diverse workplace and as the results support, larger organizations increase diversity and sensitivity training after 9/11.

Overall, the respondents of the survey felt that there has been an increased emphasis on work-life balance for their employees. Interestingly, large organizations felt that an emphasis on work-life balance by their employees increased more so than smaller organizations. The data supports the research in that due to the traumatic nature of the attacks, individuals have since started to reevaluate their priorities. As a result, individuals have looked for more work-life balance in their lives and it appears that organizations have made a conscious effort to provide that benefit to their employees. Larger organizations typically have the resources to provide such a benefit to their employees.

Implications of the research: There are many important implications that can be derived from this study. Future research could include how the effects of 9/11, along with other recent disasters/crises (i.e., Enron, the blackout in the Northeast, Hurricane Katrina) has changed the workplace. Although 9/11 was truly a day that will not be forgotten in American history, there have been many significant events that have taken place within the past ten years that have affected the workplace as well. It would be beneficial to understand how each of these events individually and collectively have affected organizations and specifically how they have affected organizational policies, employee attitudes and workers' psychological states. As more research is conducted on the implications of 9/11, additional specific studies should be conducted on each of the above mentioned issues. Currently, not enough research has been completed in this area of study to narrow down and investigate the various dimensions of each of these three issues. HR professionals in different regions throughout the United States should also be considered for study as it compares to Los Angeles and New York. 
In this specific study, the Los Angeles sample was chosen to mirror the New York Metropolitan business area due to similarities of the two areas. Survey results may be influenced by the region in which HR professionals and businesses are located. California is the most "employee friendly" state in the country and therefore is the most litigious state in the country. This may not be the case in other areas of the country and therefore research conducted in different geographic regions may produce different results. Specific regions of the country may influence the results of the survey and research and as a result, the results may have been different had the survey been administered elsewhere.

Lastly, it would be beneficial to track how 9/11 has changed human resources and organizations over time. It has been ten years since the attacks of $9 / 11$ has changed America and the way we conduct business. A study to understand the continued and future implications of 9/11 on organizations would not only benefit the field of HR, but organizations as a whole.

\section{REFERENCES}

Babcock, P., 2006. Backlash discrimination lasts five years after 9/11. Mendeley, 51: 27-40.

Bergermaier, R., I. Borg and J.E. Champoux, 1984. Structural relationships among facets of work, nonwork, and general well-being. Work Occupations, 11: 163-181. DOI: $10.1177 / 0730888484011002003$

Burke, R.J., 2005. Effects of 9/11 on individuals and organizations: Down but not out! Disaster Prevention Manage., 14: 629-638. DOI: 10.1108/09653560510634052

Catalano, R. and T. Hartig, 2001. Communal bereavement and the incidence of very low birthweight in Sweden. J. Health Soc. Behav., 42: 333-341. PMID: 11831135

Dwoskin, L. and M.B. Squire, 2003. War in the workplace: Employment issues in the post-9/11 workplace. Dechert

LLP. http://www.dechert.com/library/Auditor_Independ ence_After_Sarbanes-Oxley_7-03.pdf

Miller, B.A., 2000. We Gather Together. 1st Edn., Alfred Pub Co Inc, ISBN-10: 0874874750, pp: 4.

Hobfoll, S.E., 1989. Conservation of resources: A new attempt at conceptualizing stress. Am. Psychol., 44: 513-524. DOI: 10.1037/0003-066X.44.3.513

Holloway, H.C. and C.S. Fullerton, 1994. The Psychology of Terror and its Aftermath. In: Individual and Community Responses to Trauma and Disaster: The Structure of Human Chaos, Ursano, R.J., B.G. McCaughey and C.S. Fullerton (Eds.). Cambridge University Press, Cambridge, UK, pp: 31-45.
Jacobs, P.I. and S. Kulkarni, 1966. A test of some assumptions underlying programmed instruction. Psychol. Rep., 18: 103-110. PMID: 5908468

Judge, T.A. and S. Watanabe, 1993. Another look at the job satisfaction-life satisfaction relationship. J. Applied Psychol., 78: 939-948.

Knudsen, H.K., P.M. Roman, J.A. Johnson and L.J. Ducharme, 2005. A changed America? The effects of September 11th on depressive symptoms and alcohol consumption. J. Health Soc. Behav., 46: 260-273. DOI: 10.1177/002214650504600304

Kondrasuk, J.N., 2004. The effects of $9 / 11$ and terrorism on human resource management: Recovery, reconsideration, and renewal. Employee Responsibil. Rights J., 16: 25-35. DOI: 10.1023/B:ERRJ.0000017518.06989.85

Lazarus, R.S., 1991. Progress on a cognitivemotivational-relational theory of emotion. Am. Psychol., 46: 819-834. PMID: 1928936

Levitas, M., N. Lee and D. Barry, 2002. A Nation Challenged: A Visual History of $9 / 11$ and its Aftermath. 1st Edn., New York Times/Callaway, New York, pp: 240.

Mitroff, I.I., 2004. Think like a sociopath, act like a saint. J. Bus. Strategy, 25: 42-53. DOI: 10.1108/02756660410558933

Ryan, A., A. Mari, B.J. West and J.Z. Carr, 2003. Effects of the terrorist attacks of $9 / 11 / 01$ on employee attitudes. J. Applied Psychol., 88: 647-659.

Schlenger, W.E., J.M. Juesta, L. Ebert, B.K. Jordan and K.M. Rourke et al., 2002. Psychological reactions to terrorist attacks: Findings from the national study of Americans' reactions to September 11. J. Am. Med. Assoc., 288: 581-588. DOI: 10.1001/jama.288.5.581

Seeger, M.W., R.R. Ulmer, J.M. Novak and T. Sellnow, 2005. Post-crisis discourse and organizational change, failure and renewal. J. Organ. Change Manage., $\quad$ 18: $78-95 . \quad$ DOI: $10.1108 / 09534810510579869$

SHRM/eePulse, 2001. HR implications of the attack on America: Executive summary of results of a survey of HR professionals. Society for Human Resource Management.

http://www.eepulse.com/documents/pdfs/SHRM_R eport.pdf

Silver, R.C., E.A. Holman, D.N. McIntosh and M. Poulin et al., 2002. Nationwide longitudinal study of psychological responses to September 11. J. Am. Med. Assoc., 288: 1235-1244. DOI: 10.1001/jama.288.10.1235 
Sway, M.A., 2006. Islamophobia: Meaning, Wrzeniewski, A., 2002. It's Not Just a Job: Shifting manifestations, causes. Palestine - Israel J. http://www.islamdaily.org/en/islam/4269.islamoph obia-meaning-manifestations-causes.htm meanings of work in the wake of 9/11. J. Manage. Inquiry, $\quad$ 11: 230-234. DOI: $10.1177 / 1056492602113003$

Wortman, C.B. and R.C. Silver, 1989. The myths of coping with loss. J. Consult. Clin. Psychol., 57: 349-357. 